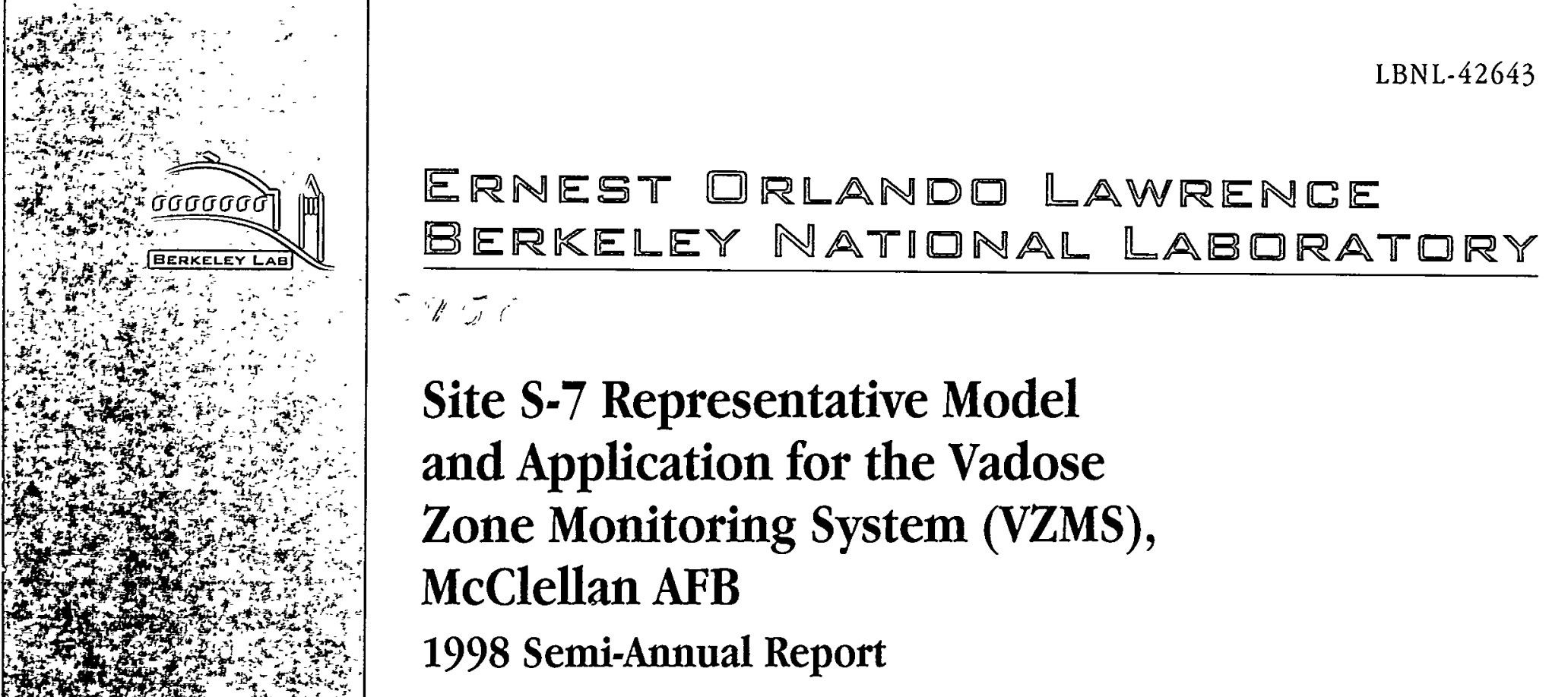




\section{DISCLAIMER}

This document was prepared as an account of work sponsored by the United States Government. While this document is believed to contain correct information. neither the United States Government nor any agency thereof, nor The Regents of the University of Calıfornia, nor any of their employees, makes any warranty, express or implied, or assumes any legal responsibility for the accuracy, completeness, or usefulnes: of any information, apparatus, product, or process disclosed, or represents that its use would not infringe privately owned rights. Reference herein to any specific commercial product, process, or service by its trade name, trademark, manufacturer, or otherwise, does not necessarily constitute or imply its endorsement, recommendation, or favoring by the United States Government or any agency thereof, or The Regents of the University of California. The views and opinions of authors expressed herein do not necessarily state or reflect those of the United States Government or any agency thereof, or The Regents of the University of California.

This report has been reproduced directly from the best available copy.

Available to DOE and DOE Contractors

from the Office of Scientific and Technical Information

P.O. Box 62, Oak Ridge, TN 37831

Prices available from $(615) \quad 576-8401$

Available to the public from the

National Technical Information Service

U.S. Department of Commerce

5285 Port Royal Road, Springfield, VA 22161

Ernest Orlando Lawrence Berkeley National Laboratory

is an equal opportunity employer. 


\section{DISCLAIMER}

Portions of this document may be illegible in electronic image products. Images are produced from the best available original document. 


\title{
Site S-7 Representative Model and Application for the Vadose Zone Monitoring System (VZMS), McClellan AFB \\ 1998 Semi-Annual Report
}

\author{
April L. James and Curtis M. Oldenburg \\ Earth Sciences Division \\ Ernest Orlando Lawrence Berkeley National Laboratory \\ Berkeley, CA 94720
}

December 15, 1998

This work was supported by the U.S. Department of Defense under Military Interdepartmental Purchase Request FD2040-96-74020EM to the Emest Orlando Lawrence Berkeley National Laboratory, managed for the U.S. Department of Energy under contract DE-AC03-76SF00098. 


\section{TABLE OF CONTENTS}

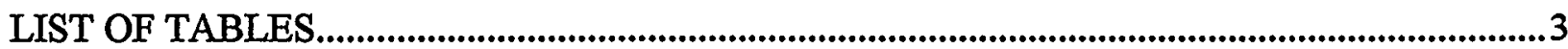

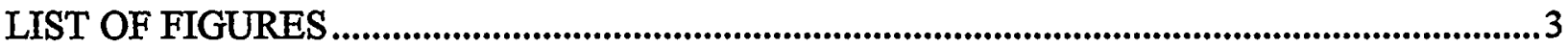

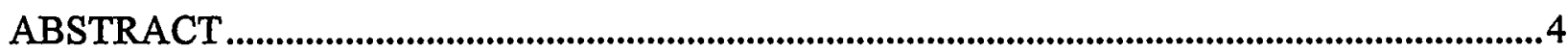

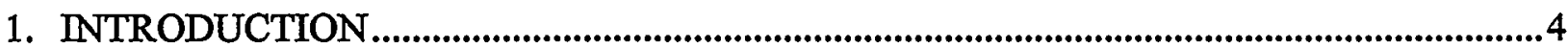

2. EVALUATION OF NEW DATA

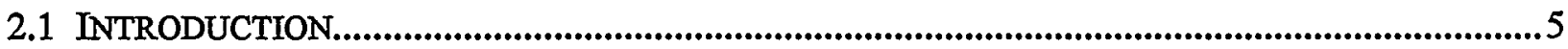

2.2 MOISTURE CONTENT..............................................................................................................................5

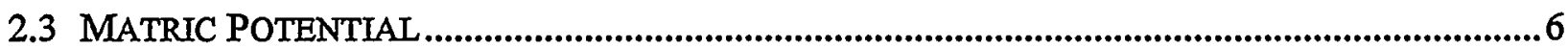

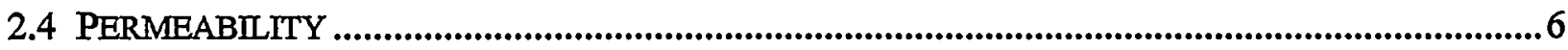

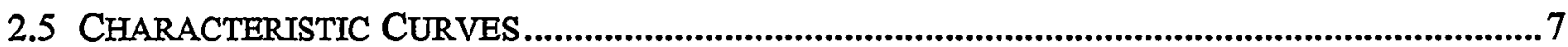

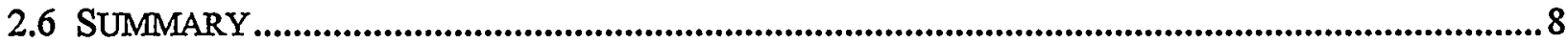

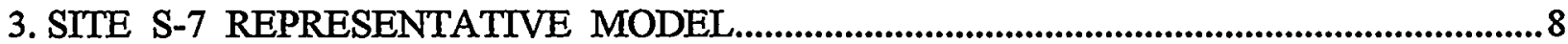

4. TCE TRANSPORT SIMULATIONS.........................................................................................9

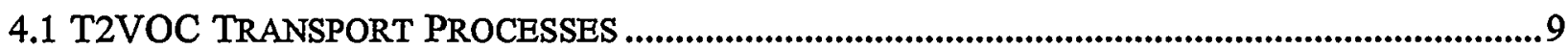

4.2 EFFECTS OF RECHARGE.............................................................................................................10

4.3 EFFECTS OF BAROMETRIC PUMPING.........................................................................

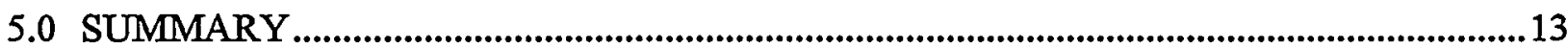

ACKNOWLEDGMENTS .................................................................................................................

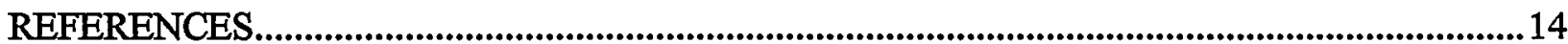




\section{LIST OF TABLES}

Table 1. Comparison of laboratory measurements and PSA estimates of permeability.................7

Table 2. Relevant TCE transport properties at $20^{\circ} \mathrm{C}$ and $1 \mathrm{~atm}$..................................................10

\section{LIST OF FIGURES}

Figure 1. Map of the S-7 site showing the location of the new boreholes: VZMS-C and Well 1. 16

Figure 2. Comparison of formation volumetric moisture content measured in sediment samples from four boreholes (VZMS-A, -B, -C, and Well 1) and in situ neutron probe data from NP-B collected on 2/5/98.

Figure 3. Comparison of matric potential from (1) tensiometers in VZMS-C, (2) laboratory analysis of sediment samples from the two most recent boreholes (VZMS-C, and Well 1), and (3) particle size analysis (PSA)..........................................................................................18

Figure 4. Comparison of model capillary pressure curves...............................................................19

Figure 5. Site S-7 representative lithologic log.................................................................................20

Figure 6. Simulated volumetric moisture content assuming a $100 \mathrm{~mm} / \mathrm{yr}$ recharge rate.................22

Figure 7. Evolution of TCE gas phase concentrations at $6 \mathrm{ft}$ resulting from a 10\% saturation NAPL source $(9.6 \mathrm{~kg})$ and recharge rates of $10,50,100$ and $200 \mathrm{~mm} / \mathrm{yr}$. 23

Figure 8. Time-varying (red) and constant (black) atmospheric pressure boundary condition....24

Figure 9. Concentrations of TCE in the gas phase resulting from a 100 ppmv source at a depth of $6 \mathrm{ft}$ using a constant atmospheric pressure boundary condition.

Figure 10. Concentrations of TCE in the gas phase resulting from a $100 \mathrm{ppmv}$ source at a depth of $6 \mathrm{ft}$ using a time varying atmospheric pressure boundary condition (see Figure 7)......26 


\section{ABSTRACT}

Vadose zone data collection and enhanced data analysis are continuing for the Vadose Zone Monitoring System (VZMS) installed at site S-7 in IC 34 at McClellan AFB. Data from core samples from boreholes drilled in 1998 and from VZMIS continuous monitoring are evaluated and compared to previously collected data and analyses. The suite of data collected to date is used to develop and constrain a spatially averaged, one-dimensional site S-7 representative model that is implemented into T2VOC. Testing of the conceptual model under conditions of recharge of 100 $\mathrm{mm} / \mathrm{yr}$ produces plausible moisture contents relative to data from several sources. Further scoping calculations involving gas-phase TCE transport in the representative model were undertaken. We investigate the role of recharge on TCE transport as well as the role of diffusion and gas-phase flow driven by density and barometric pumping effects. This report provides the first example of the application of the site S-7 representative model in the investigation of subsurface VOC movement.

\section{INTRODUCTION}

In this report, we present further enhanced data analysis for the S-7 site in IC 34 at McClellan AFB. The enhanced data analysis described in the prior 1998 semi-annual report (LBNL, 1998b) is extended by the incorporation of new data to create a spatially averaged, onedimensional site S-7 representative model for T2VOC simulations. The new data come from the construction of two new boreholes, VZMS-C and Well 1. The Vadose Zone Monitoring System (VZMS) (LBNL, 1996) now consists of three instrumented boreholes (VZMS-A, -B, -C), Well 1 , and two neutron probe boreholes (NP-A, -B) extending over an area of approximately $400 \mathrm{ft}^{2}$. The VZMS and neutron probe collect detailed site-specific temporal data on hydraulic potential, soil-gas pressure, moisture content, water chemistry, gas chemistry, and temperature. The purposes of this report are to (1) present a comparison and evaluation of new data from lithologic logs, laboratory measurements of sediment samples, and data collected by the VZMS, (2) introduce the site S-7 representative model developed by spatially averaging site data from all available boreholes, and (3) illustrate the application of the site S-7 representative model for enhanced data analysis by showing the results of TCE transport simulations. The simulations show the effects of diffusion, density-driven flow, variable barometric pressure boundary conditions, and recharge on TCE transport in the vadose zone. The methods used in the T2VOC model were described in the appendix of a prior report (LBNL, 1998b). 


\section{EVALUATION OF NEW DATA}

\subsection{Introduction}

Since the June 1998 semi-annual report (LBNL, 1998b), we have obtained new data on the properties of the subsurface formation at site S-7 from two sources: (1) data measured from cores collected during the drilling of boreholes VZMS-C and Well 1 in April 1998; and (2) data from the tensiometers in VZMS-C. In this section, we compare these new data with prior data and prior modeling results as an overall check of the consistency of both our data and our data analysis methods. The comparison and evaluation are made by simple graphical displays and discussion.

Core samples were collected during the drilling of boreholes VZMS-C and Well 1 (Figure 1) in April 1998. The cores were sent to Daniel B. Stephens \& Associates (DBS\&A) for measurement of porosity, moisture content, permeability, and van Genuchten capillary pressure function parameters (D.B. Stephens and Associates, 1998). After well construction, we installed tensiometers in VZMS-C. These tensiometers have produced reliable data on in situ matric potential down to a depth of 15 feet (LBNL, 1998a). In the enhanced data analysis presented in the semi-annual report of June 1998, we used particle size analysis (PSA) data measured by the BSK laboratory (BSK) (LBNL, 1996) to derive van Genuchten parameters for the sediments. These derived parameters and corresponding characteristic curves will also be compared against the new data from DBS\&A and the tensiometers in VZMS-C.

\subsection{Moisture Content}

Prior enhanced data analysis (LBNL, 1998b) utilized neutron probe data as constraints on moisture content for the VZMS-B T2VOC conceptual model. It is useful to compare the moisture content data collected by the neutron probe in borehole NP-B with samples collected in the two new boreholes (VZMS-C and Well 1), analyzed by D.B. Stephens and Associates (1998). These data are plotted in Figure 2. The neutron probe data calibration was based on BSK moisture content data and as such, the match between neutron probe and data from VZMS$A$ and VZMS-B is prescribed. It is important to note that in the alluvial braided stream depositional setting of the S-7 subsurface, differences in sediment type can occur over short distances in the vertical and horizontal directions. Generally, we observe moisture content data from DBS\&A and BSK/neutron probe to follow similar trends with depth. Therefore, while the details of moisture contents at any level may show variation, there is good overall agreement of moisture contents determined by the various methods. This comparison provides confirmation of the effectiveness of the neutron probe in providing measurements of moisture content similar 
to those determined in the lab. The consistency of moisture contents from the various boreholes also supports the use of a single site S-7 representative model (see Section 3).

\subsection{Matric Potential}

Particle size analysis (PSA) was used to derive van Genuchten parameters for prior enhanced data analysis (LBNL, 1998b). The new dataset allows a comparison of the PSA method against laboratory measurements and in situ tensiometer data. Plotted in Figure 3 are matric potential data from (1) the tensiometers in VZMS-C, (2) laboratory measurements of samples from VZMS-C and Well 1, and (3) PSA using data from similar levels in adjacent boreholes. Moisture retention of the sediments was estimated using Vereecken's (1988) equations as presented in the earlier semi-annual report (LBNL, 1998b).

Figure 3 shows several interesting features of the various data sources. First, starting from a shallow depth, we observe good agreement between all three methods to a depth of about 15 feet. We used the lithologic log and our best judgment for correlating the DBS\&A samples with prior BSK samples. We emphasize that the PSA is done using data from different samples and different boreholes from the samples analyzed by DBS\&A (VZMS-C and Well 1). For the samples between 18 and 30 feet, the PSA method gives moisture potentials much more negative than the two laboratory measurements of samples from the same depth. Because the sediments in the middle part of Figure $3(35-65 \mathrm{ft})$ were similar to sediments found higher in the section, we did not collect samples from these areas for the laboratory determination of matric potential. Moving downwards from 70 feet, the PSA once again agrees moderately well to very well with the laboratory measurements. The second important feature of the data is that the matric potential is predominately in the range of -100 to $-300 \mathrm{mbar}$. With the stainless steel porous cup used for the VZMS-A and B tensiometers (from which no data are shown in Figure 3) having an air-entry pressure of approximately -250 mbar, it is apparent that the formation is near the limit of the range of the tensiometers. Based on our experiences with the tensiometers in VZMS-A and $\mathrm{B}$, we used tensiometers with larger (more negative) air-entry pressures in the new installation in VZMS-C.

\subsection{Permeability}

The next comparison of data and analysis concerns the absolute permeability. We used empirical relationships provided by Bear (1972), Jabro (1992), and Shiozawa and Campbell (1991) to estimate permeability based on PSA in our prior work (LBNL, 1998b). New data on permeability (saturated hydraulic conductivity) were obtained by DBS\&A by constant head and falling head method (D.B. Stephens and Associates, 1998). The laboratory measurements and PSA estimates are presented in Table 1 for comparison. Given the large range in values of 
permeability for natural materials as well as the well-known scale effects of permeability (Brace 1980; Clauser 1992), the PSA methods compare relatively well with laboratory measurements.

\subsection{Characteristic Curves}

As a final comparison, we present the characteristic curves derived using the van Genuchten parameters (van Genuchten, 1980) measured by DBS\&A along with the PSA-derived characteristic curves used in our prior report (LBNL, 1998b). We plot in Figure 4 the capillary pressure vs. saturation because this is used in the T2VOC model rather than matric potential and moisture content. The various samples show a wide range of characteristic curves consistent with the heterogeneous sediments present. In addition, the four generalized sediment types which were previously defined (LBNL, 1998b) and which were based on PSA from samples collected during the initial VZMS installation in December 1995 encompass the entire range of samples analyzed by DBS\&A. This gives further credence to the particle size analysis in general, with a caution that the generalized sediment type "sandy silt" based on PSA (LBNL 1998b) may overpredict capillary pressure.

Table 1. Comparison of laboratory measurements and PSA estimates of permeability.

\begin{tabular}{|l|l|l|l|}
\hline depth of sample $(\mathrm{ft})$ & sediment name & $\begin{array}{l}\text { laboratory } \\
\text { measurement } \\
\left(\log \mathrm{k}\left[\mathrm{m}^{2}\right]\right)\end{array}$ & $\begin{array}{l}\text { correlation based on } \\
\text { PSA }\left(\log \mathrm{k}\left[\mathrm{m}^{2}\right]\right)\end{array}$ \\
\hline $3.5-4$ & RCK1 & -13.92 & $\dagger$ \\
\hline $8.5-9$ & RCK2 & -12.74 & $-10.98^{*}$ \\
\hline $12-12.5$ & RCK3 & -11.77 & $-12.24^{*}$ \\
\hline $17.5-18$ & RCK4 & -12.44 & $-10.84^{*}$ \\
\hline $29-29.5$ & RCK5 & -11.96 & $-11.42 \dagger \dagger$ \\
\hline $69.5-70$ & RCK6 & -10.96 & $-9.79 \dagger \dagger$ \\
\hline $79-79.5$ & RCK7 & -12.15 & $-11.73+\dagger$ \\
\hline $79.5-80$ & RCK8 & -12.17 & $-12.10+\dagger$ \\
\hline $109-109.5$ & RCK9 & -11.00 & $-9.73+\dagger$ \\
\hline
\end{tabular}

PPSA not performed at this depth.

*Equation of Jabro (1992) using silt and clay fractions and density.

of Kozeny-Carmen equation (Bear, 1972) with method of Shiozawa and Campbell (1991) to estimate mean particle diameter. 


\subsection{Summary}

The data we have collected on moisture content, matric potential, and permeability from various sources are generally consistent. In the absence of laboratory or in situ data, PSA appears to be a satisfactory approach in many cases. While PSA can produce matric potential estimates that agree closely with laboratory data, PSA can also produce matric potentials that disagree with laboratory measurements. When laboratory or in situ data are available, we will use these data in current and future enhanced data analysis. Finally, we can infer with some confidence that the inability of the tensiometers in VZMS-A and B to provide reliable moisture potential data is due to the formation having matric potentials more negative than the air-entry pressure of the stainless steel porous cups.

\section{SITE S-7 REPRESENTATIVE MODEL}

Because the data collected at site S-7 come from several different boreholes, there is a need for a spatially averaged model. This representative model must be broadly consistent with each borehole, but may not necessarily coincide with any one borehole in particular. The objective is to develop a conceptual model that is representative of the S-7 subsurface in general, so that data collected at all of the various VZMS boreholes can be used as constraints on the representative model. Recognizing that the primary interest at site S-7 is on vertical VOC transport, we chose to develop a one-dimensional model that is a plausible spatial average of the area encompassed by VZMS boreholes.

The spatially averaged, one-dimensional site S-7 representative model has been developed using old and new data. In addition to older data described in the previous semi-annual report (LBNL 1998b), the S-7 dataset now includes data evaluated in Section 2 of this report, namely the lithologic logs for VZMS-C and Well 1, the laboratory-measured values of absolute permeability and van Genuchten capillary pressure function parameters, and matric potential data from VZMS-C tensiometers. The spatially averaged conceptual model is developed as a one-dimensional column representing the general sequence of lithologies from four boreholes (VZMS-A, -B, -C and Well 1).

The creation of a spatially averaged S-7 model began with the development of a spatially averaged lithologic log. By visually comparing the four lithologic logs, we observed the general spatial trends and the salient features representing the overall sequence of sediment types. This was performed in close consultation with the geologist who was present during drilling of the most recent boreholes (VZMS-C and Well 1) and who had selected sampling depths that were analyzed by DBS\&A for permeability and van Genuchten capillary pressure function 
parameters. Selection of sampling depths was based on assessing the borehole geology for sediment types that were representative of the various sediments within the vadose zone. Samples were collected from nine depths in all for analysis by DBS\&A. In the selection of this number of samples, it was thought that all relevant sediment types present in the subsurface at S7 would be characterized. Correspondingly, nine sediment types, one for each analyzed sample, were defined and then distributed throughout the spatially averaged, site S-7 representative model. Figure 5 illustrates the resulting S-7 site representative model with the lithologic log shown on the left-hand side and the hydrogeologic parameters measured by DBS\&A on the righthand side. Hydrogeologic parameters include absolute permeability, and van Genuchten capillary pressure curve parameters of air entry pressure, $1 / \alpha, n$ and residual moisture content, $\theta_{x}$. Because no site data existed for the layers of concrete and gravel filling, an additional sediment type with low permeability was prescribed for the T2VOC simulations (Sediment Type 6).

\section{TCE TRANSPORT SIMULATIONS}

\subsection{T2VOC Transport Processes}

T2VOC models multicomponent (water, air, VOC), multiphase (gas, aqueous, NAPL), and nonisothermal subsurface flow and transport (Falta et al., 1995). Using a multiphase expression of Darcy's Law, all phases may be mobile depending on the local pressure gradient, gravitational force, effective permeability, and phase viscosity. Each phase can transport the VOC component by advection. Molecular diffusion is modeled for the gas phase only while hydrodynamic dispersion is neglected. Equilibrium partitioning of the components occurs between all phases with the exception of water transfer into the NAPL phase. The VOC component partitions into the gas and aqueous phases as described by Henry's Law and is linearly adsorbed onto porous media. In summary, transport of VOCs in T2VOC occurs by advection of the gaseous, aqueous, and NAPL (if present) phases, and by molecular diffusion in the gas phase. The properties of TCE as used in the simulations are presented in Table 2, unless otherwise noted.

Based on the various physical properties of TCE shown in Table 2, we can make some predictions of the importance of various processes. For example, the high density of TCE vapor means that TCE can move downward by density-driven gas-phase flow (Falta et al., 1989). Gasphase diffusion may also be an important transport mechanism. The volatile nature of TCE as 
specified by the Henry's constant ensures that TCE can spread by gas-phase flow from its NAPL source to surrounding regions and partition into the aqueous phase. We assume in the simulations presented here that TCE is not undergoing any biodegradation or chemical transformation. Organic carbon in the sediments can lead to TCE adsorption, a process modeled in T2VOC through distribution coefficients and the assumption of local equilibrium. The fraction organic carbon is variable in the domain as defined in the S-7 site representative model lithologies.

Table 2. Relevant TCE transport properties at $20^{\circ} \mathrm{C}$ and $1 \mathrm{~atm}$.

\begin{tabular}{|l|c|c|l|}
\hline \multicolumn{1}{|c|}{ Parameter } & Value & Units & \multicolumn{1}{|c|}{ Comment } \\
\hline Density of saturated vapor & 1.58 & $\mathrm{~kg} \mathrm{~m}^{-3}$ & $\begin{array}{l}\text { Density of air at } 1 \mathrm{~atm}, 20^{\circ} \mathrm{C} \text { is } \\
1.19 \mathrm{~kg} \mathrm{~m}^{-3} .\end{array}$ \\
\hline Viscosity of saturated vapor & $1.7 \times 10^{-5}$ & $\mathrm{~kg} \mathrm{~m}^{-1} \mathrm{~s}^{-1}$ & $\begin{array}{l}\text { Viscosity of air at } 1 \mathrm{~atm}, 20^{\circ} \mathrm{C} \text { is } \\
1.8 \times 10^{-5} \mathrm{~kg} \mathrm{~m}^{-1} \mathrm{~s}^{-1} .\end{array}$ \\
\hline Reference TCE diffusivity, gas phase & $8 \times 10^{-6}$ & $\mathrm{~m}^{2} \mathrm{~s}^{-1}$ & $\begin{array}{l}\text { TCE diffusivity is affected by } \\
\text { local pressure and temperature } \\
\text { (Falta et al., 1995). }\end{array}$ \\
\hline Inverse Henry's constant & $4.77 \times 10^{7}$ & $\mathrm{~Pa}$ & Equilibrium phase partitioning. \\
\hline TCE degradation rate & 0.0 & $\mathrm{~kg} \mathrm{~s}-1$ & We assume TCE is conservative. \\
\hline Fraction of organic carbon (FOC) & variable & - & $\begin{array}{l}\text { Value varies with lithology. } \\
\text { FOC causes adsorption of TCE. }\end{array}$ \\
\hline
\end{tabular}

\subsection{Effects of Recharge}

Using the site S-7 representative model, a simulation was performed to establish a steadystate moisture profile based on gravity-capillary equilibrium and steady-state recharge. We initialize the system assuming that gravity and capillarity exactly balance, and we assign each gridblock the corresponding liquid saturation to satisfy this gravity-capillary equilibrium assumption. This system is then run to steady state, as indicated by the T2VOC time step size approaching very large values $\left(\sim 10^{10} \mathrm{~s}\right)$. We then use this steady state as an initial condition for a simulation where we prescribe recharge of water at the top of the column at a constant rate and 
we run this to steady state. After comparing several different assumed recharge rates, we selected a rate of $100 \mathrm{~mm} / \mathrm{yr}$ as plausible based on agreement with moisture content data. Figure 6 illustrates the moisture content profile in comparison with site S-7 data as previously shown in Figure 2. The moisture contents that result from $100 \mathrm{~mm} / \mathrm{yr}$ of recharge appear to match the site S-7 data relatively well. For 1997, McClellan AFB received an estimated $500 \mathrm{~mm}$ of precipitation (NOAA National Data Centers [NNDC] webpage: http: //www.nndc.noaa.gov/phase3/productaccm/htm). Averaged over a given area, some fraction of this precipitation, depending on run-off and evapotranspiration, would infiltrate the subsurface.

To investigate the impact of constant recharge on TCE transport in the site S-7 representative model column, we performed a series of simulations in which we observed the dissolution and downward transport of an initial TCE source of 10\% NAPL saturation (amounting to $9.6 \mathrm{~kg}$ ) located at a depth of $6 \mathrm{ft}$. Four different recharge rates are prescribed. Figure 7 shows the evolution of gas phase concentrations at the location of the initial NAPL source $(6 \mathrm{ft})$ with prescribed recharge rates of $10,50,100$ and $200 \mathrm{~mm} / \mathrm{yr}$. Initially, we observe gas phase concentrations at a maximum value of $0.39 \mathrm{~kg} / \mathrm{m}^{3}$ ( $\sim 71$ parts per thousand by volume) based on the saturated vapor pressure of TCE and equilibrium phase partitioning of the NAPL into the gas and aqueous phases. For the smallest recharge $(10 \mathrm{~mm} / \mathrm{yr})$, no decrease in concentrations is observed, indicating that NAPL is still present after 30 years. Given a rate of $50 \mathrm{~mm} / \mathrm{yr}$, NAPL is dissolved from the $6 \mathrm{ft}$. depth after roughly 5 years. Gas phase concentrations after 30 years are still very high ( 25 parts per thousand by volume). The $100 \mathrm{~mm} / \mathrm{yr}$ recharge rate washes out the NAPL source within 4 years and, at 30 years, leaves gas phase concentrations on the order of 1000 ppmv. In doubling this recharge, NAPL is removed about a year earlier and concentrations are very small ( $233 \mathrm{ppbv})$ thirty years later.

Based on this series of simulations, with the assumption of an initial 10\% NAPL source (9.6 $\mathrm{kg}$ ) and a constant recharge rate slightly higher than $100 \mathrm{~mm} / \mathrm{yr}$, after 30 years TCE concentrations at a depth of $6 \mathrm{ft}$ decline to roughly $100 \mathrm{ppmv}$, on the order of what is observed at the S-7 site. While the concentrations at $6 \mathrm{ft}$ can be modeled with a constant and uniform recharge scenario, the simulated concentrations in the middle part of the column disagree with the VZMS data. In particular, the VZMS data show peaks in TCE concentration at shallow depths of roughly 5-10 ft and again at the depth of the water table ( 112 ft) (LBNL, 1998a). At depths between these two peaks, VZMS data show that TCE concentrations are very low. The simulations do not show this bimodal distribution of TCE in the column. Thus, while the preliminary simulations, that include recharge, point to the importance of downward TCE transport, the VZMS data on TCE concentrations show that the middle of the column contains no evidence for this downward movement. 
The assumptions involved in these simulations are many. Recharge rates are constant and do not allow for seasonal fluctuations. TCE is distributed throughout the various phases and sorption sites assuming local equilibrium. The column. is one-dimensional and does not allow for flow bypassing or channeling which could effectively shelter local NAPL from dissolution by recharge (Kung, 1990). And recent studies (e.g., Imhoff et al., 1993; Powers et al., 1994; Armstrong et al., 1994) suggest that nonideal and transient dissolution of TCE NAPL may be more realistic than the assumption of local equilibrium as currently used in T2VOC. These issues will continue to be investigated to better assess the importance of recharge-driven downward fluxes of VOCs.

\subsection{Effects of Barometric Pumping}

Investigation of the effects of barometric pumping on gas phase VOC movement within the one-dimensional representative column was performed by prescribing a 100 ppmv gas phase TCE concentration at a depth of $6 \mathrm{ft}$ and simulating TCE movement over one year. The simulation was repeated with two distinct boundary conditions prescribed at the ground surface: (1) a constant atmospheric pressure boundary condition and (2) a time-varying atmospheric pressure boundary condition. Both boundary conditions are illustrated in Figure 8 . The timevarying pressure is based on data obtained directly from the VZMS at site S-7 during 1997. For the constant pressure boundary condition case, we specify pressure as the average of the timevarying data. We use the steady-state moisture profile established using a $100 \mathrm{~mm} / \mathrm{yr}$ recharge rate as shown in Figure 6. The liquid phase is kept immobile during these simulations so that the effects of diffusion and density-driven gas-phase flow can be isolated.

Figure 9 illustrates the evolution of TCE concentrations in the gas phase within the site S-7 representative model, given a constant atmospheric pressure boundary condition of 1.0128 bar. Concentrations are shown at 3,6,11,18 and $30 \mathrm{ft}$ depths. At the depth of the initial TCE source ( $6 \mathrm{ft}$ ), we observe decreasing concentrations of TCE from $100 \mathrm{ppmv}$ to $2 \mathrm{ppmv}$. Concentrations below this depth increase over time due to the movenent of TCE by diffusion and density-driven flow. After 1 year, concentrations at 11, 18 and $30 \mathrm{ft}$ depths have risen to values of $1.9 \mathrm{ppmv}$, $4.3 \mathrm{ppmv}$ and $.0007 \mathrm{ppbv}$, respectively. TCE may also move upwards through the column towards and into the atmospheric boundary via gas phase diffusion. The upper boundary will act as a sink for upward moving TCE just as the groundsurface does in venting into the atmosphere. For example, note that TCE concentrations at $3 \mathrm{ft}$ rise to a value of $3.5 \mathrm{ppbv}$.

In order to study the effects of barometric pumping, the simulation was repeated with a timevarying atmospheric boundary condition. Figure 10 illustrates gas-phase TCE concentrations at the same 5 observation depths shown in Figure 9. Elarometric pumping has increased the speed 
with which TCE travels downward. For instance, concentrations at $18 \mathrm{ft}$ appear roughly 45 days earlier when the time varying pressure boundary is applied. For a depth of $30 \mathrm{ft}$ this decrease in travel time is at least 90 days. The simulation results also show the response of TCE gas phase concentrations to the high pressure signal from day 310 to 330 (see Figure 8). With the increase in atmospheric pressure, concentrations at shallow depths of 3 and $6 \mathrm{ft}$ show a marked dip to values of .0014 and $2.5 \mathrm{ppbv}$, respectively, as compared to values of 3.5 and $1900 \mathrm{ppbv}$ in Figure 9. A smaller dip in concentrations is seen at $11 \mathrm{ft}$ (from $4.3 \mathrm{ppmv}$ in Figure 9 to $1.4 \mathrm{ppmv}$ in Figure 10). The high pressure pulse is forcing clean air downwards from the groundsurface into shallow regions, while forcing TCE-contaminated soil gas downwards from the contaminated regions. Thus, concentrations at depths greater than 18 and $30 \mathrm{ft}$ show a rise beginning at day 310.

With this simple application of the site S-7 representative model, we continue to investigate the importance of various physical processes in reproducing VOC profiles similar to the site S-7 VZMS data. The simulation results presented here provide a comparison of the effects of two distinct boundary conditions: constant and time-varying atmospheric pressure. The comparison illustrates the potential importance of including barometric pumping in the simulation of subsurface TCE movement and the ability of T2VOC and ITOUGH2 (Finsterle, 1997) to incorporate a time varying boundary condition.

\subsection{SUMMARY}

New data have been collected at the S-7 site giving more information on lithology of the vadose zone, values of matric potential from both soil samples and tensiometers, values of absolute permeability, and van Genuchten capillary pressure function parameters. Comparison of volumetric moisture content data from core samples and neutron probe readings appear consistent and allow us to draw a moisture content profile to constrain the site S-7 representative model and the selection of a plausible recharge rate. Matric potential data from tensiometers (VZMS-C) and core samples (VZMS-C and Well 1) seem to indicate a range of values that provide an explanation for why tensiometers in VZMS-A and -B are unable to provide reliable readings. Estimation of matric potential using regression curves based on particle size analysis (PSA) from the scientific literature is shown to have varied success in predicting site S-7 values but is a reasonable approach when no other data exist. PSA was also shown to have produced van Genuchten capillary pressure curves bounding the behavior of core samples analyzed by DBS\&A. Simulation of a TCE NAPL source and the evolution of concentrations at depth using the site S-7 representative T2VOC model has provided a first example of what features and 
physical processes may be important to include in the conceptual model to produce a VOC profile similar to that observed at the S-7 site.

\section{ACKNOWLEDGMENTS}

We thank Stefan Finsterle and Peter Zawislanski for helpful reviews. This work was supported by the U.S. Department of Defense under Military Interdepartmental Purchase Request FD2040-96-74020EM to the Ernest Orlando Lawrence Berkeley National Laboratory, managed for the U.S. Department of Energy under contract DE-AC03-76SF00098.

\section{REFERENCES}

Armstrong, J. E. , E. O. Frind, and R. D. McClellan, 1994, Nonequilibrium mass transfer between the vapor, aqueous, and solid phases in unsaturated soils during vapor extraction, Water Resour. Res., 30(2), 355-368.

Bear, J., 1972, Dynamics of Fluids in Porous Media. New York, Dover Publications, Inc., 764 p.

Brace, W.F., 1980, Permeability of crystalline and argillaceous rocks, Int. J. Rock Mech. Min. Sci. and Geomech. Abstr., 17, 241-251.

Clauser, C., 1992, Permeability of crystalline rocks, EOS, Transactions of the American Geophysical Union, 73(21), pp. 233 and 237, (May 26, 1992).

Daniel B. Stephens \& Associates, 1998, Inc., Hydraulic Properties of Lawrence Berkeley National Laboratory Soil Samples, (July 21, 1988).

Falta, R. W., K. Pruess, S. Finsterle, and A. Battistelli., 1995, T2VOC User's Guide, Lawrence Berkeley Laboratory Report, LBL-36400, Berkeley, California.

Falta, R.W., and I. Javandel, K. Pruess, and P.A. Witherspoon, 1989, Density-driven flow of gas in the unsaturated zone due to the evaporation of volatile organic compounds, Water Resour. Res., 25(10), 2159-2169.

Finsterle, S., 1997a, ITOUGH2 Command Reference, Lawrence Berkeley National Laboratory Report, LBNL-40041, Berkeley, California, (April, 1997).

Imhoff, P. T., P. R. Jaffe, and G. F. Pinder, 1993, An experimental study of complete dissolution of a nonaqueous phase liquid in saturated porous media, Water Resour. Res., 30(2), 307-320. 
Jabro, J. D., 1992, Estimation of Saturated Hydraulic Conductivity of Soils From Particle Size Distribution and Bulk Density Data, Transactions of the ASAE, 35(2), 557-560.

Kung, K-J.S., 1990, Preferential flow in a sandy vadose zone: 1. Field observation, Geoderma, $46,51-58$.

LBNL, 1996, Vadose Zone Monitoring System Installation Report for McClellan AFB. Prepared by Zawislanski, P.T., B. Faybishenko, A. James, B. Freifeld, and R. Salve, Report to the Department of the Air Force, McClellan AFB, Lawrence Berkeley Laboratory Report, LBL39525, Berkeley, Califomia, (October, 1996).

LBNL, 1998a, Data Analysis for Preliminary Conceptual Model Design, Vadose Zone Monitoring System (VZMS), McClellan AFB. Prepared by Zawislanski, P. T. and C. M. Oldenburg, Annual Report to the Department of the Air Force, McClellan AFB, (January, 1998).

LBNL, 1998b, Enhanced Data Analysis for the VZMS: Conceptual Model Design and Initial Application for the Vadose Zone Monitoring System (VZMS), McClellan AFB. Prepared by James, A. L. and C. M. Oldenburg, Semi-Annual Report to the Department of the Air Force, McClellan AFB, Lawrence Berkeley Laboratory Report, LBL-41909, Berkeley, California, (June, 1998).

Powers, S. E., L. M. Abriola and W. J. Weber Jr., 1994, An experimental investigation of nonaqueous phase liquid dissolution in saturated subsurface systems: Transient mass transfer rates, Water Resour. Res., 30(2), 321-332.

Shiozawa, S. and G. S. Campbell, 1991, On the Calculation of Mean Particle Diameter and Standard Deviation From Sand, Silt, and Clay Fractions, Soil Science, 152(6), 427-431.

van Genuchten, R., 1980, Predicting the Hydraulic Conductivity of Unsaturated Soils, Soil Sci. Soc. Am. Proc., 44, 892-898.

Vereecken, H., 1988, Pedotransfer Functions for the Generation of Hydraulic Properties of Belgian Soils, $\mathrm{PhD}$ thesis, Katholieke Universiteit Leuven, Leuven, Belgium, $254 \mathrm{pp}$. 

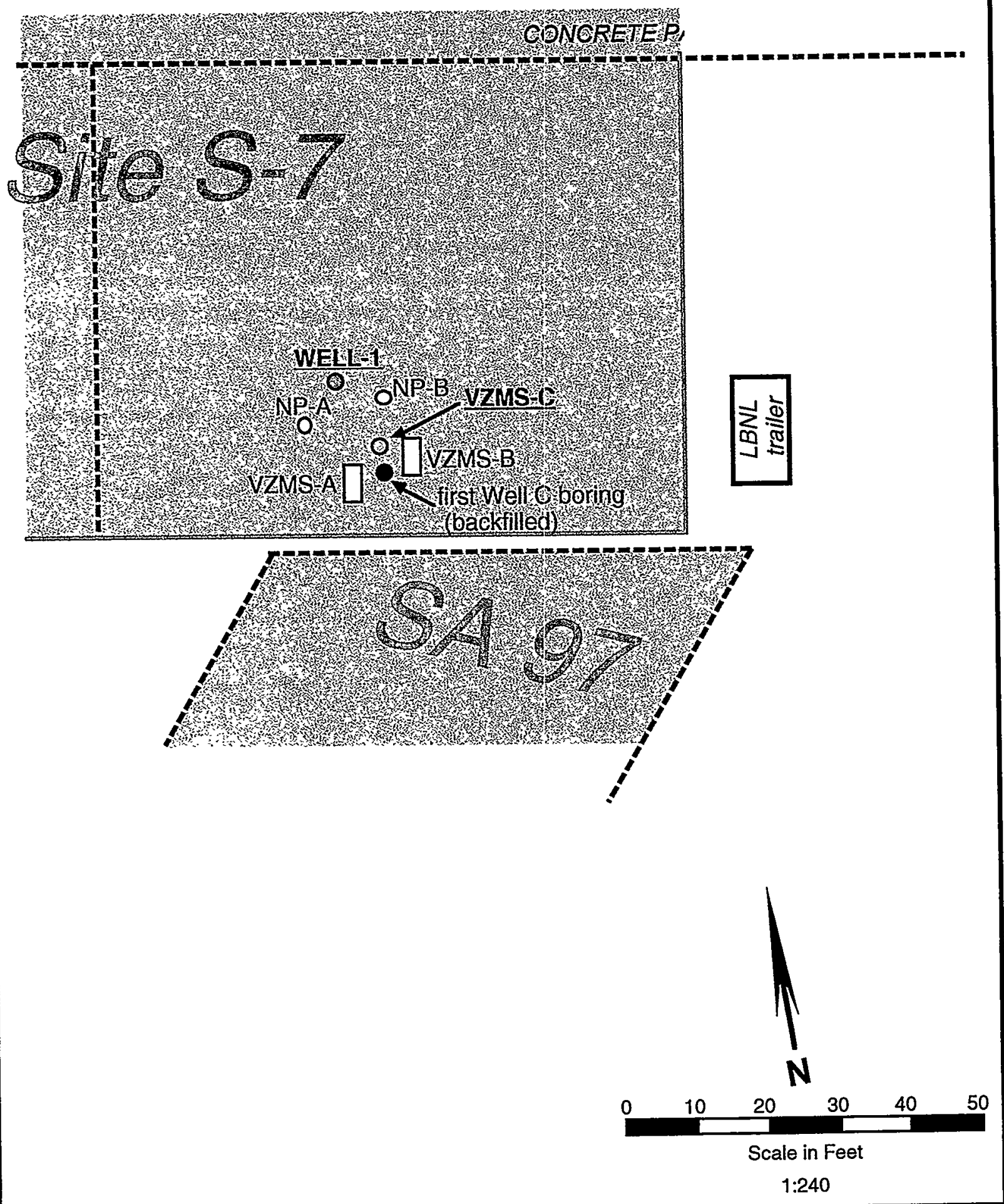

Figure 1. Map of the S-7 site showing the location of the new boreholes: VZMS-C and Well 1. 


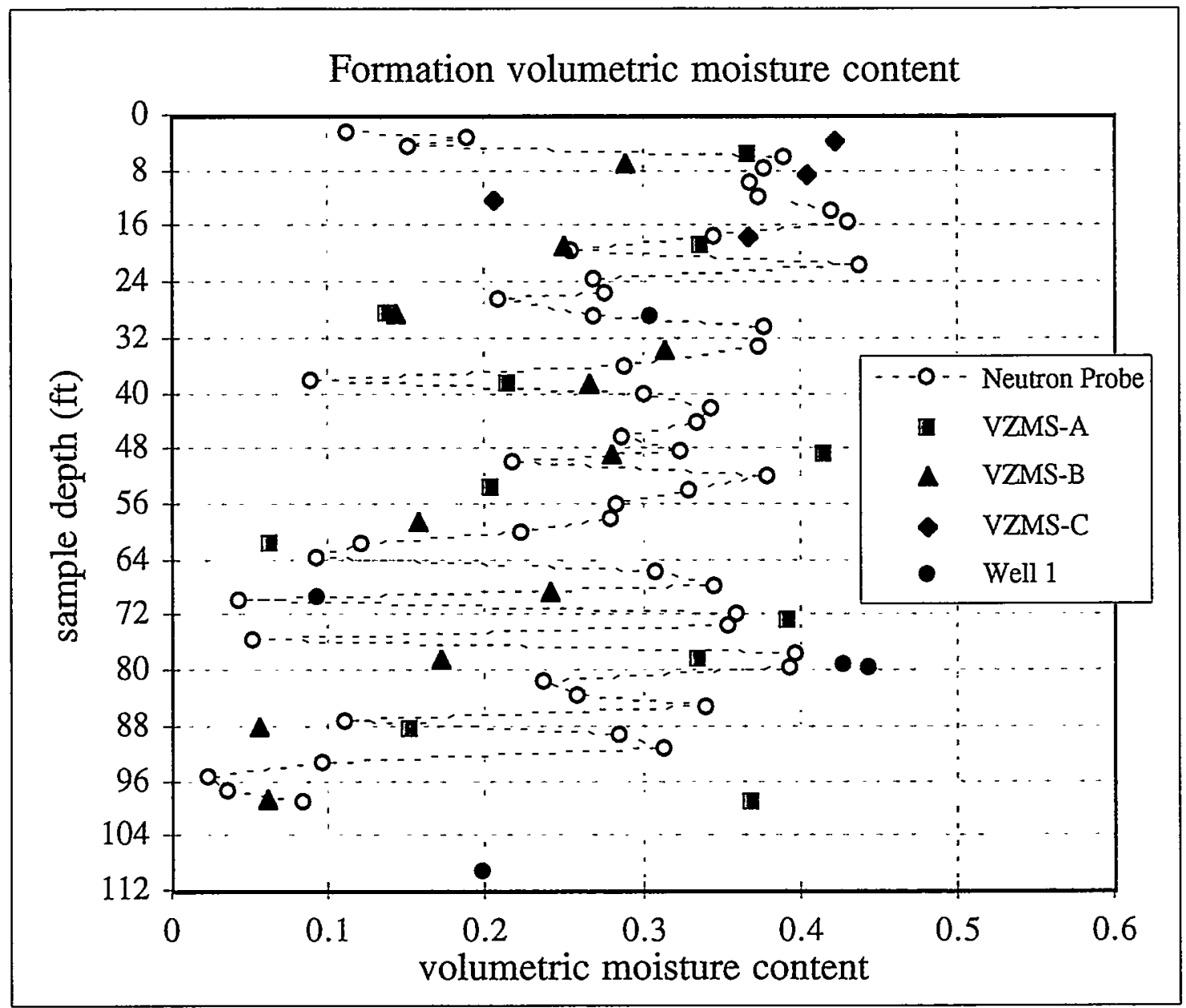

Figure 2. Comparison of formation volumetric moisture content measured in sediment samples from four boreholes (VZMS- $A,-B,-C$, and Well 1) and in situ neutron probe data from NP-B collected on 2/5/98. Neutron probe data is calibrated using data from VZMS-A and $-B$. 


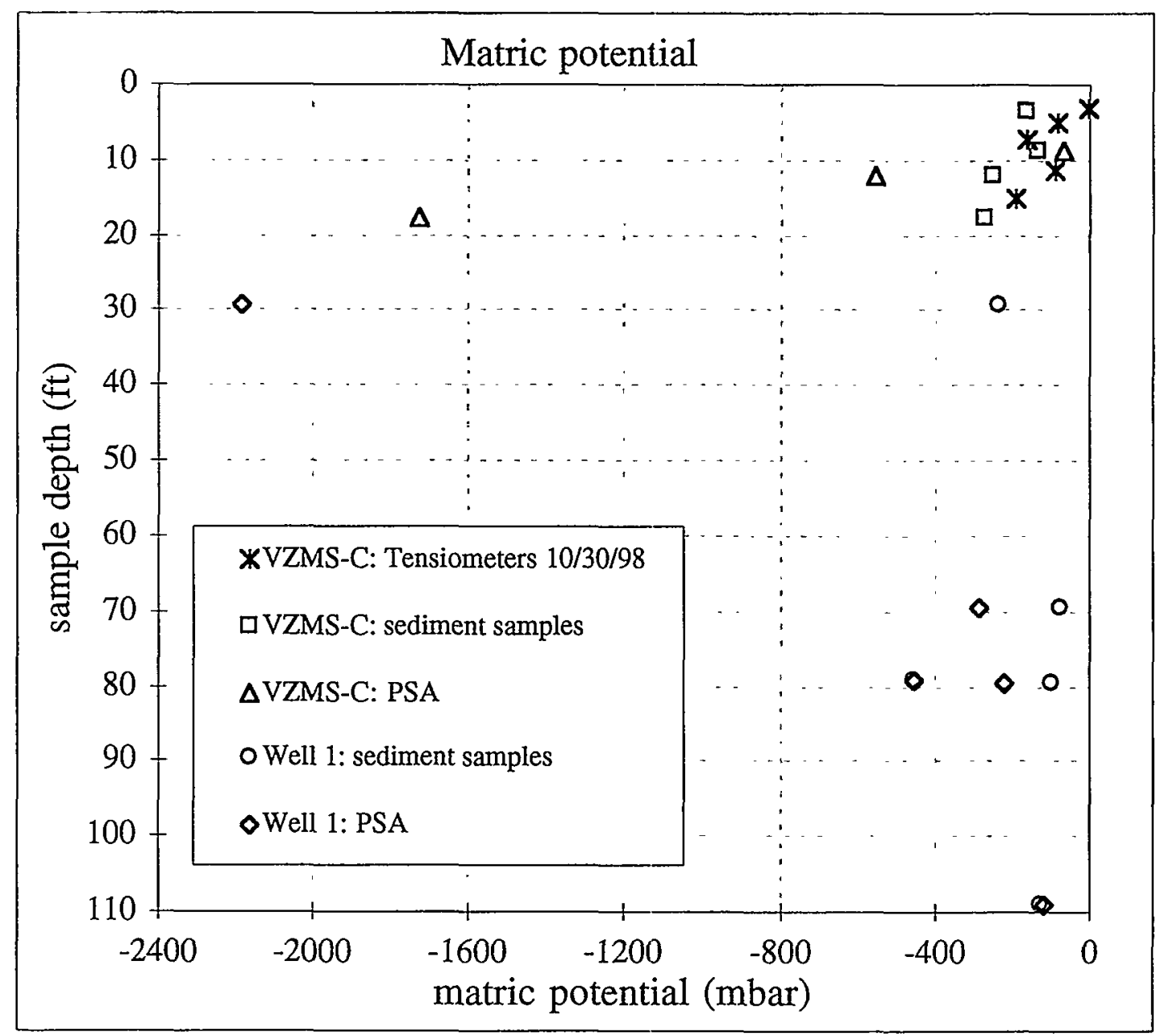

Figure 3. Comparison of matric potential from (1) tensiometers in VZMS-C, (2) laboratory analysis of sediment samples from the two most recent boreholes (VZMS-C, and Well 1), and (3) particle size analysis (PSA). 


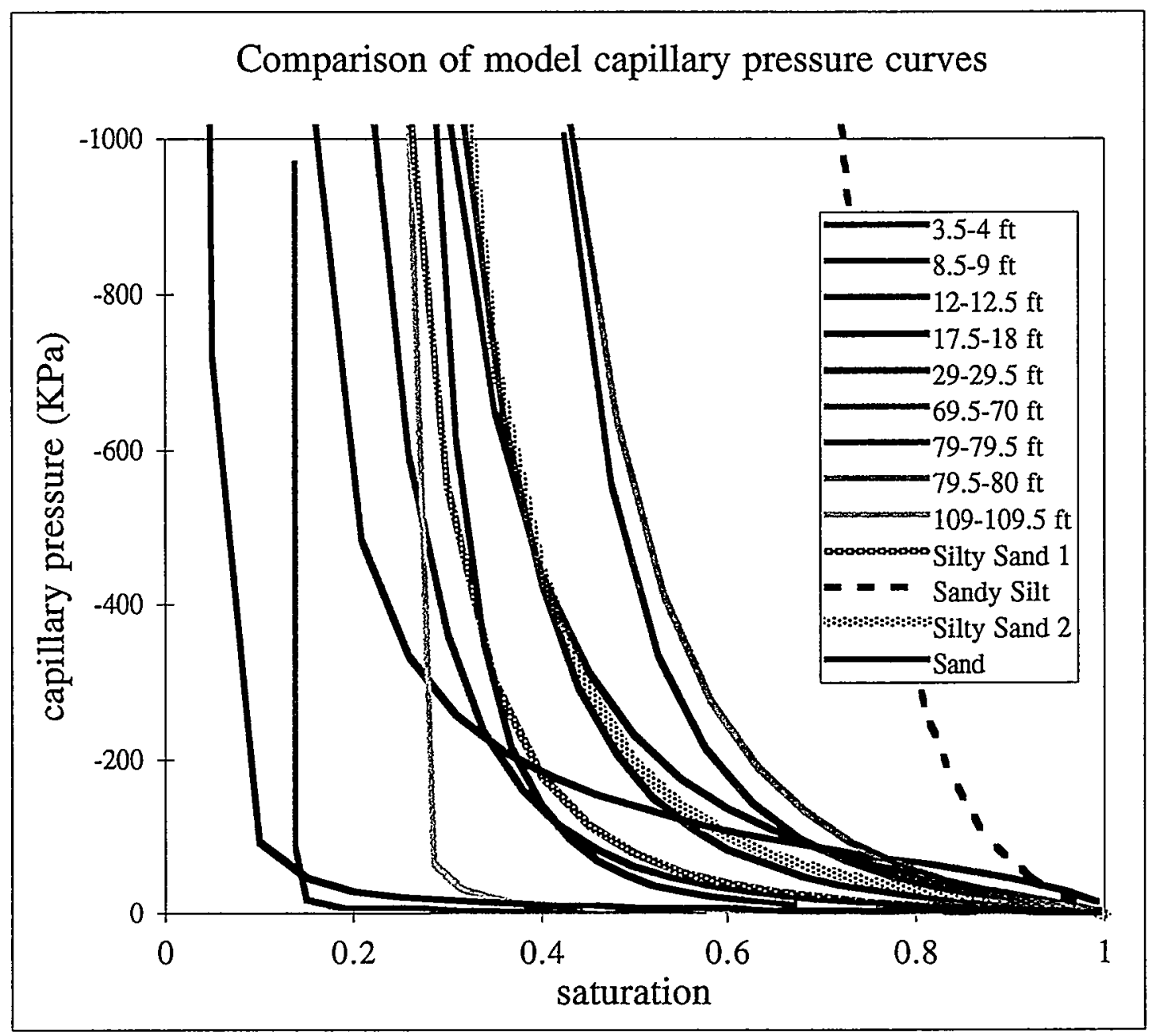

Figure 4. Comparison of model capillary pressure curves. 


\begin{tabular}{|c|c|c|c|c|c|}
\hline $\begin{array}{r}\text { Site S-7 Represen } \\
\text { DEPTHT } \\
\text { app }\end{array}$ & $\begin{array}{l}\text { Ie } \\
\text { DWATE } \\
\mathrm{ft}\end{array}$ & oncep & ual M & odel & \\
\hline T2VOC S-7 Conceptual Model Log & \multirow{2}{*}{ 㣉售 } & \multicolumn{4}{|c|}{ Hydrogeologic Parameters } \\
\hline DESCRIPTION AND REMARKS & & $\begin{array}{l}\text { Permeability } \\
\text { (log k[m.2]); } \\
\text { darcies }\end{array}$ & $\begin{array}{c}\text { yan } \\
\text { Genuchten } \\
1 / \alpha(\mathrm{Pa})\end{array}$ & $\begin{array}{c}\operatorname{van} \\
\text { Genuchten } \\
\mathrm{n}\end{array}$ & $\begin{array}{l}\mathrm{Sr} \\
(90)\end{array}$ \\
\hline $\begin{array}{l}\text { Filling } \\
\text { Concrete top } 4 \text { inches; roadbase gravel fill to } 1.5 \mathrm{ft} \\
2 \text { inches aspbalt, roadbase gravel fill to } 3 \mathrm{ft} \text {. }\end{array}$ & & see text & for attribute & d properti & s \\
\hline Silty Sand (SM): SEDIMENT TYPE 1 & & logk $=-13.92$ & 21800 & 1.31 & .1758 \\
\hline Clayey Silt (ML):SEDIMENT TYPE 2 & & $\begin{array}{l}\log \mathrm{k}=-12.74 \\
\mathrm{k}=.18 \text { darcies }\end{array}$ & 44590 & 1.48 & .0995 \\
\hline Sand (SM-SP): SEDIMENT TYPE 3 & & $\begin{array}{l}\log \mathrm{k}=-11.77 \\
\mathrm{k}=1.7 \text { darcies }\end{array}$ & 2087 & 1.28 & .1329 \\
\hline Sandy Silt (ML): SEDIMENT TYPE 2 & 15 & $\begin{array}{c}\log k=-12.74 \\
k=.18 \text { darcies }\end{array}$ & 44590 & 1.48 & .0995 \\
\hline Sitty Sand (SM):SEDIMENT TYPE 4 & 20 & $\begin{array}{l}\log k=-12.44 \\
k=.36 \text { darcies }\end{array}$ & 12418 & 1.26 & .0039 \\
\hline Sandy Silt (ML-SM): SEDIMENT TYPE 5 & 2 & $\begin{array}{l}\log k=-11.96 \\
k=1.1 \text { darcies }\end{array}$ & $605 t$ & 1.29 & .0001 \\
\hline Sand layer (SM-SP): SEDIMENT TYPE 3 & $30-$ & $\log _{k} k=-1.7$ darcies & 2087 & 1.28 & .1329 \\
\hline Silt (ML): SEDIMENT TYPE 2 & & $\begin{array}{l}\log k=-12.74 \\
k=.18 \text { darcies }\end{array}$ & 44590 & 1.48 & .0995 \\
\hline Silty Sand (SM): SEDIMENT TYPE 4 & & $\begin{array}{l}\log k=-12.44 \\
k=.36 \text { darcies }\end{array}$ & 12418 & 1.26 & .0035 \\
\hline Clayey Silt (ML): SEDIMENT TYPE 2 & & $\begin{array}{l}\log k=-12.74 \\
k=.18 \text { darcies }\end{array}$ & 44590 & 1.48 & .0995 \\
\hline
\end{tabular}

Figure 5. Site $S-7$ representative lithologic log. 


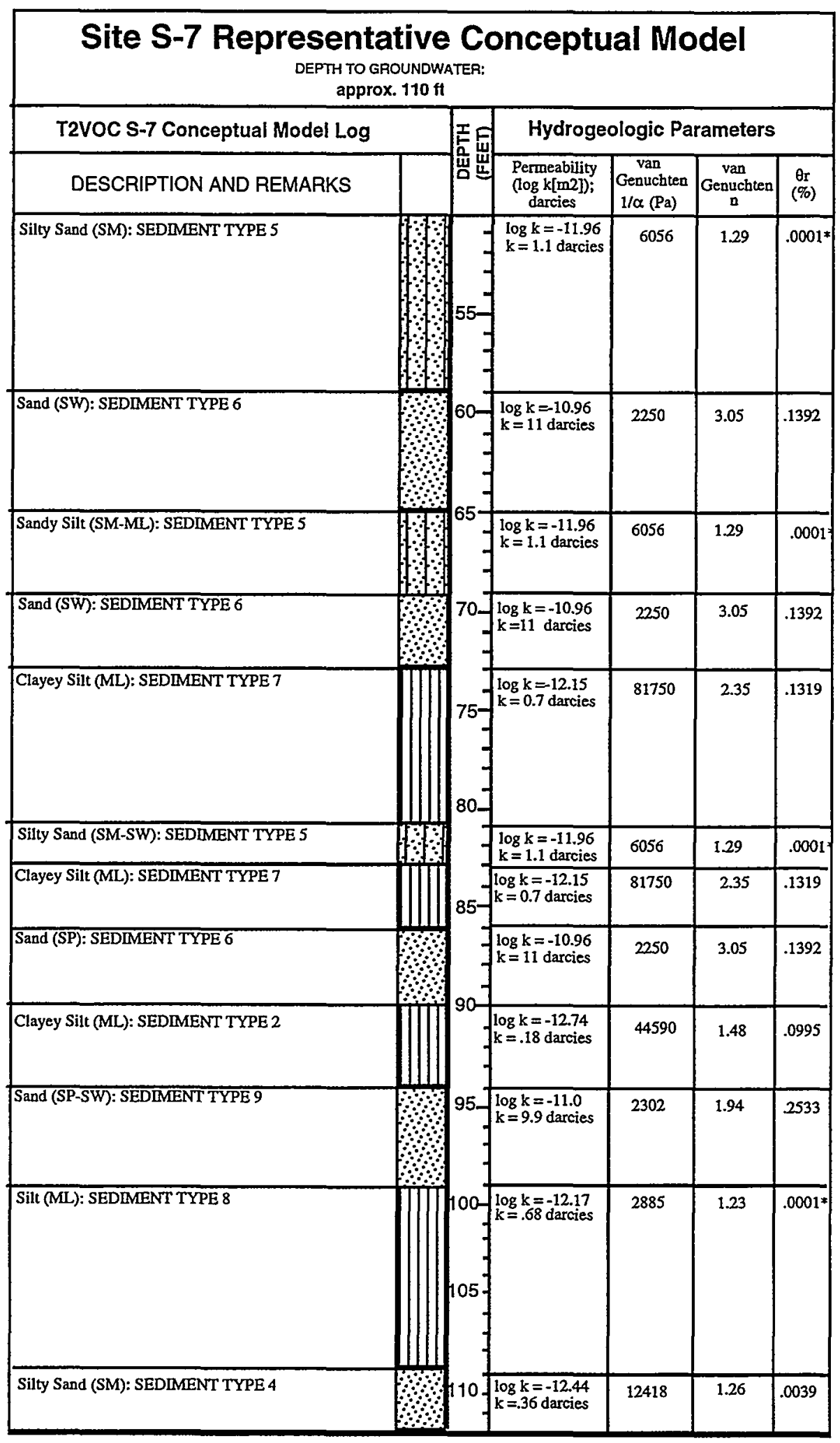

Figure 5 continued. Site S-7 representative lithologic log. 


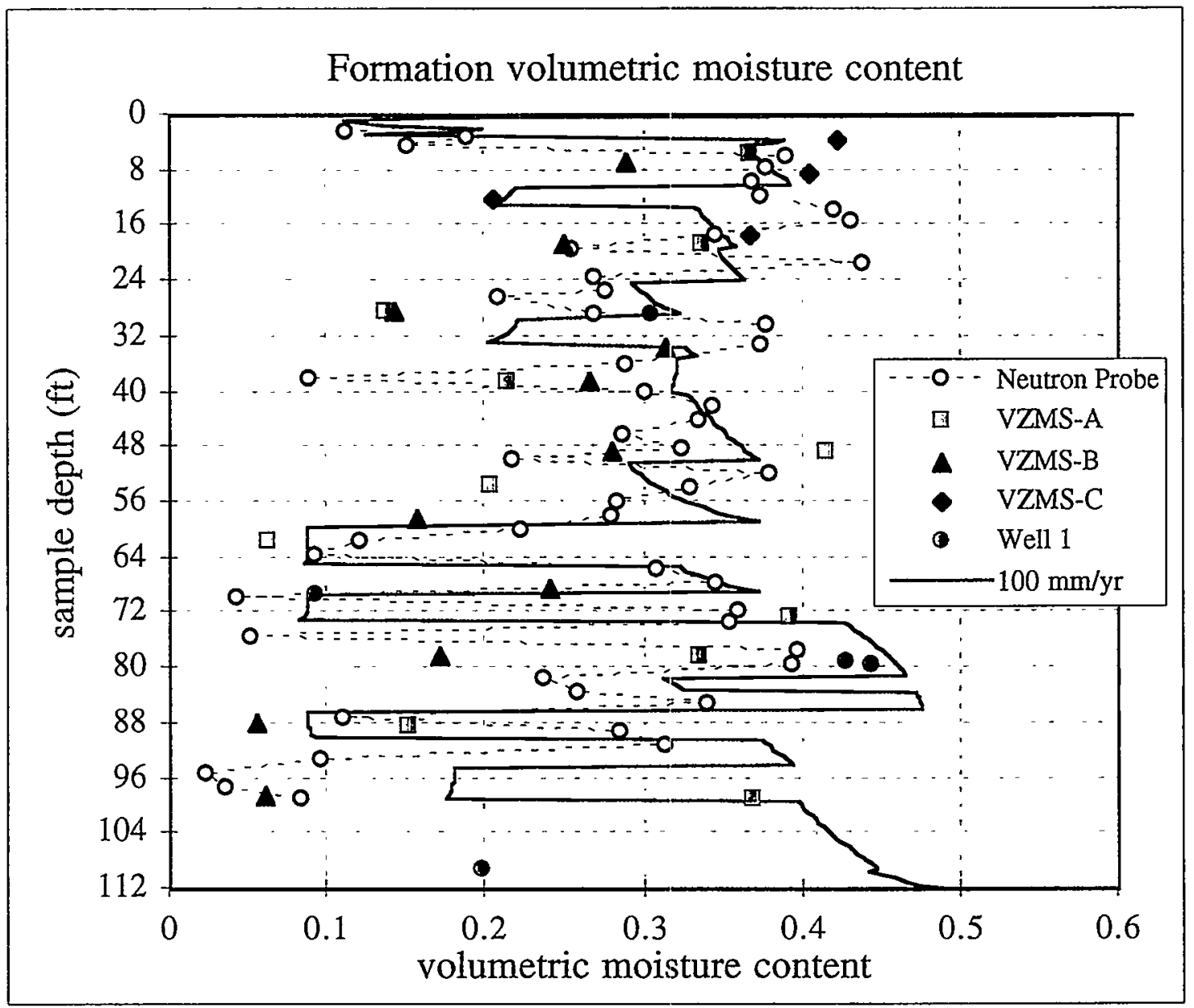

Figure 6. Simulated volumetric moisture content assuming a $100 \mathrm{~mm} / \mathrm{yr}$ recharge rate. 


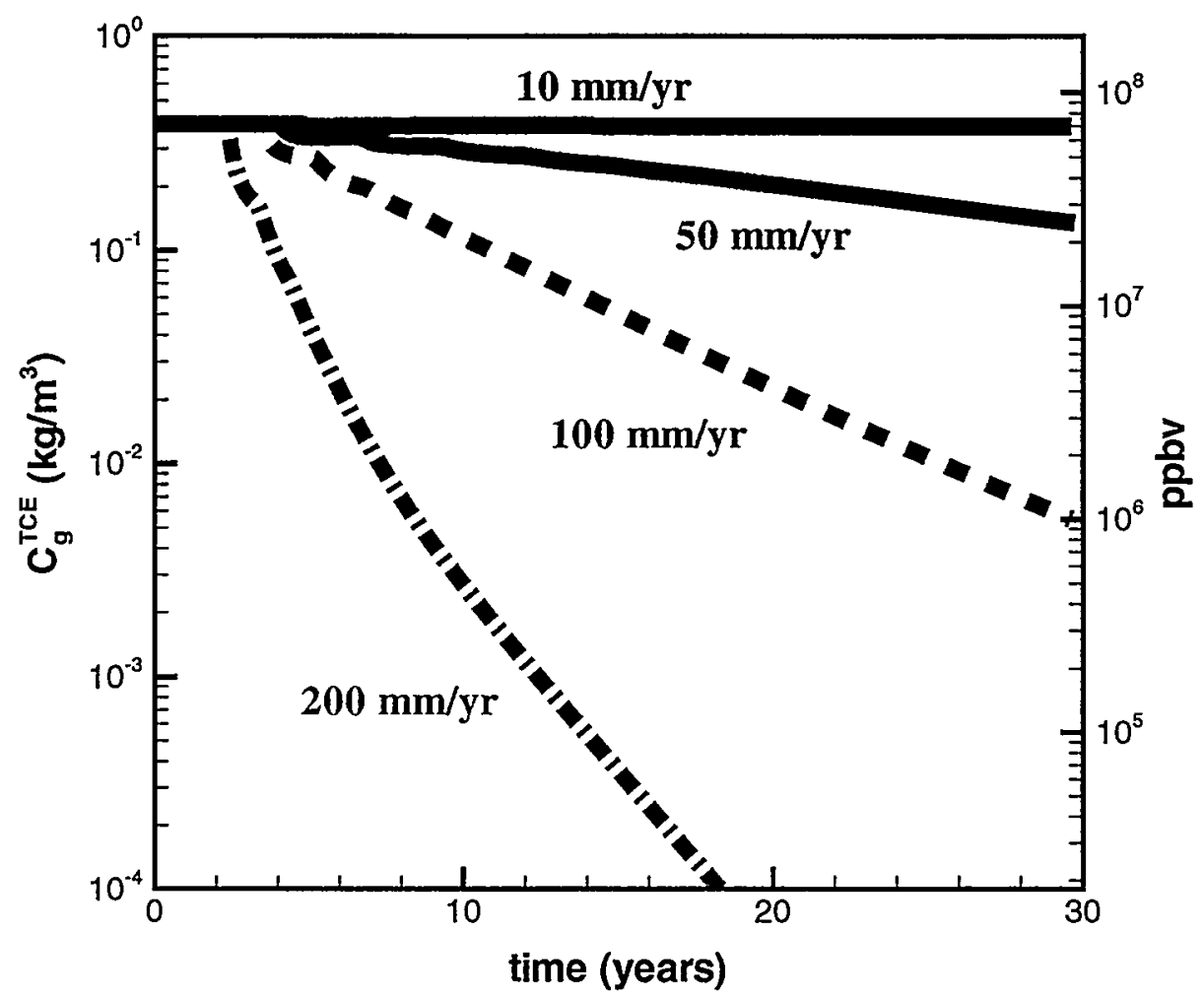

Figure 7. Evolution of TCE gas phase concentrations at 6 f resulting from a $10 \%$ saturation NAPL source (9.6 kg) and recharge rates of $10,50,100$ and $200 \mathrm{~mm} / \mathrm{yr}$. 


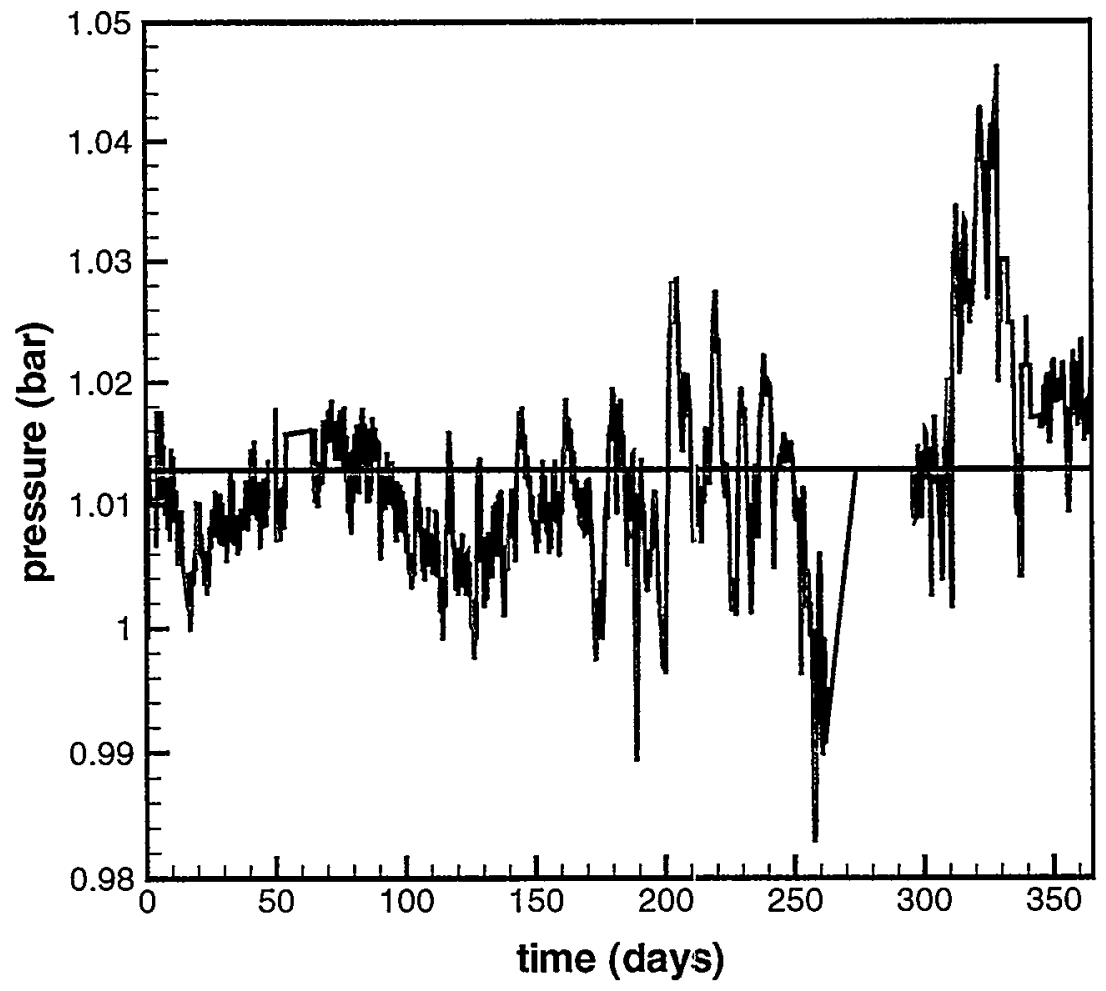

Figure 8. Time-varying (red) and constant (black) atmospheric pressure boundary condition. 


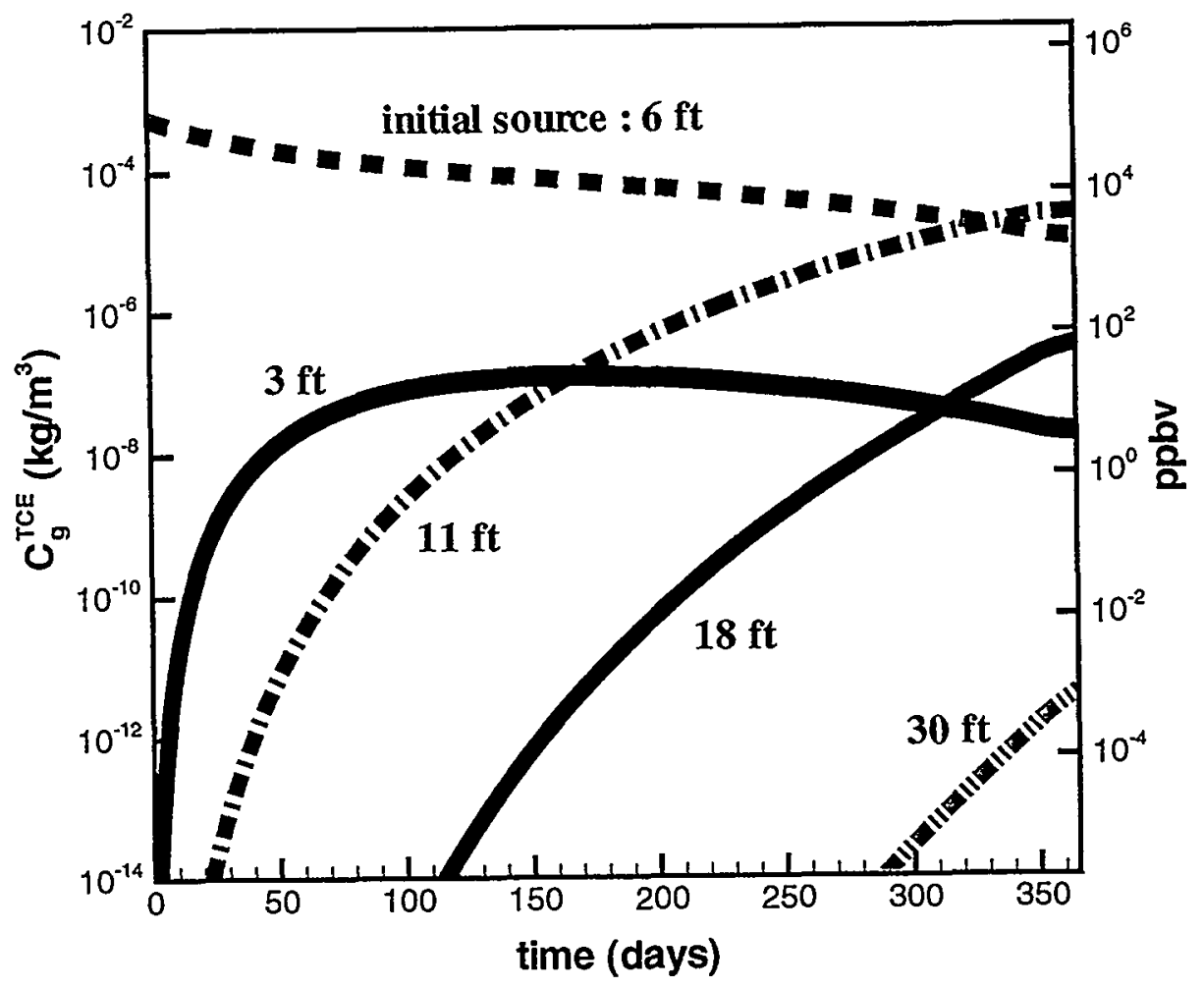

Figure 9. Concentrations of TCE in the gas phase resulting from a 100 ppmv source at a depth of 6 ft using a constant atmospheric pressure boundary condition. 


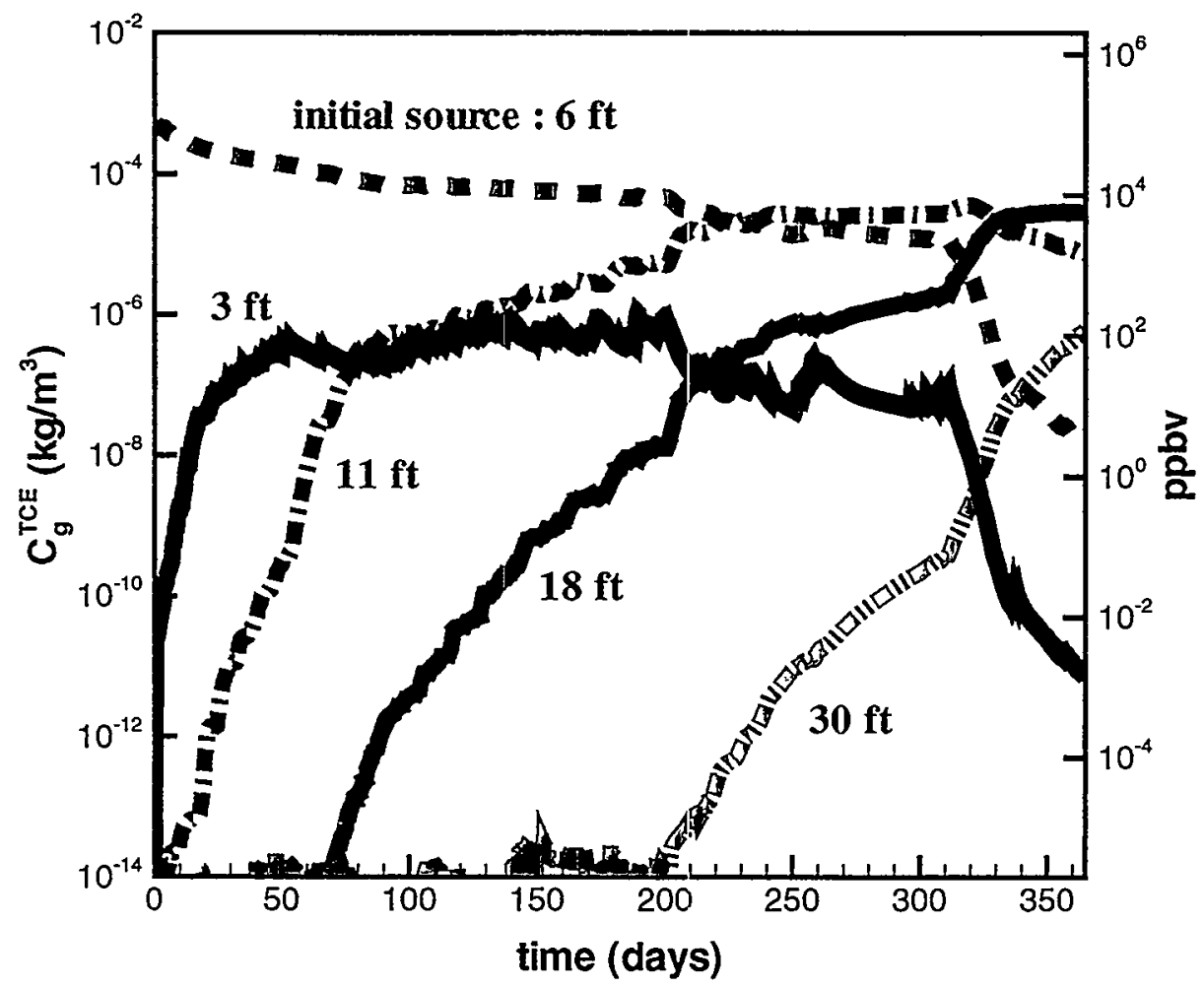

Figure 10. Concentrations of TCE in the gas phase resulting from a 100 ppmv source at a depth of $6 f t$ using a time varying atmospheric pressure boundary condition (see Figure 7). 